\title{
Hubungan Tingkat Pengetahuan Ibu Hamil Tentang Anemia Dengan Risiko Kejadian BBLR
}

\author{
Siti Fatimah ${ }^{1}$, Nopita Dewi Kania ${ }^{2}$ \\ 1,2 Program Studi Kebidanan, Universitas Galuh Ciamis \\ e-mail : sitifatimah446611@gmail.com \\ (Diterima 16-02-2019; disetujui 10-04-2019; dipublish 09-05-2019)
}

\begin{abstract}
Abstrak
Angka Kematian Bayi (AKB) di Indonesia masih tergolong tinggi. BBLR merupakan salah satu penyebab kematian neonatal, di samping Trauma Lahir, Asfiksia, Infeksi, Tetanus Neonatorum (TN), Kelainan Bawaan dan Lain-lain. Peningkatan pengetahuan ibu hamil merupakan upaya strategi dalam pencapaian penurunan angka kematian bayi. Penelitian ini bertujuan untuk mengetahui Hubungan Tingkat Pengetahuan Ibu Hamil Tentang Anemia Dengan Risiko Kejadian BBLR Di Wilayah Kerja Puskesmas Baregbeg Tahun 2018. Desain penelitian yang digunakan adalah deskriptif analitik yang menggunakan desain cross sectional study. Alat ukur yang digunakan dalam penelitian ini adalah lembar kuesioner untuk mengidentifikasi tingkat pengetahuan ibu hamil tentang anemia dan lembar observasi untuk mengetahui tinggi fundus uteri ibu untuk menghitung taksiran berat badan janin sehingga dapat melihat risiko atau tidak risiko kejadian BBLR. Teknik pengambilan sampel yang digunakan yaitu accidental sampling dengan jumlah sampel sebanyak 15 orang. Hasil uji korelasi Chi-Square diperoleh nilai sebesar 0,596 dengan nilai $\rho$ value sebesar 0,016 . Nilai $\rho$ value sebesar 0,016 lebih kecil dari $\alpha$ $(0,05)$. Ibu yang memiliki tingkat pengetahuan yang baik sebanyak 7 orang $(46,6 \%)$ dan ibu yang tidak berisiko kejadian BBLR sebanyak 10 orang $(66,6 \%)$. Hal ini menunjukkan bahwa terdapat hubungan yang signifikan antara tingkat pengetahuan ibu hamil tentang anemia dengan risiko kejadian BBLR. Pengetahuan ibu hamil tentang anemia sangat penting sebagai salah satu upaya pencegahan terjadinya anemia pada saat hamil dan risiko kejadian BBLR. Diharapkan dapat menambah pengetahuan ibu tentang anemia pada ibu hamil dan mencegah risiko kejadian BBLR serta sebagai pengembangan ilmu pengetahuan dan metodologi penelitian.
\end{abstract}

Kata Kunci : Tingkat Pengetahuan, Wanita Hamil, Berat Badan Lahir Rendah, Anemia.

\begin{abstract}
Infant Mortality Rate (IMR) in Indonesia is still relatively high. LBW is one of the causes of neonatal death, in addition to Birth Trauma, Asphyxia, Infection, Tetanus Neonatorum (TN), Congenital Abnormalities and Others. Increasing the knowledge of pregnant women is a strategic effort in achieving the decrease of infant mortality rate. This study aims to determine the relationship between the knowledge level of pregnant mothers about anemia with the risk of BBLR occurrence in the working area of Baregbeg Puskesmas 2018. The research design used is analytical descriptive using cross sectional study design. The measuring tool used in this study is a questionnaire sheet to identify the level of knowledge of pregnant women about anemia and observation sheet to determine the height of the mother's uterine fundus to calculate the estimated weight of the fetus so that it can see the risk or not risk of $L B W$ occurrence. The sampling technique used was accidental sampling with a total sample of 15 people. Chi-Square correlation test results obtained value of 0.596 with a value of $\rho$ value of 0.016. The value of $\rho$ value of 0.016 is smaller than $\alpha$ (0.05). Mothers with a good level of knowledge of 7 people $(46.6 \%)$ and mothers who did not risk the occurrence of BBLR as many as 10 people (66.6\%). This shows that there is a significant correlation between maternal knowledge level about anemia with risk of LBW occurrence. Maternal knowledge about anemia is very important as one of prevention of anemia during pregnancy and risk of $L B W$ incidence. Expected to increase mother's knowledge about anemia in pregnant mother and prevent the risk of occurrence of $L B W$ as well as development of science and research methodology.
\end{abstract}

Keywords : Knowledge Level, Pregnant Woman and Low Birth Weight, Anemia. 


\section{PENDAHULUAN}

Anemia pada ibu hamil adalah kondisi ibu dengan kadar hemoglobin $(\mathrm{Hb})$ dalam darahnya kurang dari $1 \mathrm{~g} / \mathrm{dL}$ anemia selama kehamilan akibat peningkatan volume darah merupakan anemia ringan. Anemia yang lebih berat, bagaimanapun dapat meningkatkan risiko tinggi pada bayi. Selain itu, jika secara signifikan terjadi anemia pada ibu hamil selama dua trimester (trimester 2 dan trimester 3), maka berisiko lebih besar untuk memiliki berat badan bayi lahir rendah (BBLR). ${ }^{1}$

Apabila kadar Hb (Haemoglobin) kurang dalam darah berarti kemampuan darah dalam mengikat dan membawa oksigen akan berkurang, demikian pula zat-zat nutrisi yang dibawa oleh sel-sel darah merah juga akan berkurang. Keadaan ini menyebabkan janin kekurangan zat makanan dan oksigen sehingga janin mengalami gangguan pertumbuhan dan pada waktu lahir bayi tersebut lahir dengan berat badan rendah. BBLR adalah bayi yang baru lahir dengan berat badan saat lahir kurang 2500 gram. $^{2}$

Kesehatan ibu dan anak merupakan indikator penting dalam mengukur derajat kesehatan suatu negara, dimana status kesehatan ibu dan anak dapat dilihat dari Angka Kematian Ibu (AKI) dan Angka Kematian Bayi (AKB). AKI di Indonesia mencapai 305/100.000 KH dan AKB 23/1000 $\mathrm{KH}$ Penyebab kematian ibu adalah hipertensi dalam kehamilan, perdarahan dan infeksi sedangkan pada bayi disebabkan oleh gangguan pernafasan, BBLR, infeksi dan kelainan bawaan. ${ }^{3}$

Prevalensi BBLR diperkirakan $15 \%$ dari seluruh kelahiran di dunia dengan batasan 3,3\%-38\% dan lebih sering terjadi di negara berkembang dan angka kematiannya 35 kali lebih tinggi dibanding pada bayi dengan Berat Badan Lahir Normal. Diperkirakan sekitar 17 juta bayi lahir BBLR setiap tahun dan 16\% diantaranya lahir di negara berkembang. ${ }^{2}$

Theresa O Scholl (2012) dalam Maternal Iron status: Relation to Fetal Growth, Lenght of Gestation and the Neonate's Iron Endowment di Nigeria menyimpulkan bahwa kekurangan zat besi pada ibu hamil dapat menyebabkan kematian bayi $54 \%$, selain itu dapat menyebabkan BBLR (6,8-15\%), asfiksia
(4,1\%-11\%). Anemia merupakan masalah mikro terbesar di Indonesia, dimana terjadi pada kelompok balita, anak sekolah, ibu hamil, wanita dan laki-laki dewasa. ${ }^{4}$

Laporan Dinas Kesehatan Kabupaten/Kota tahun 2012, diketahui bahwa jumlah bayi dengan Berat Badan Lahir Rendah (BBLR) di Jawa Barat mencapai 2.1\% yang diperoleh dari persentase 18,997 bayi dari 912.208 bayi baru lahir yang ditimbang. ${ }^{3}$ dan pada tahun 2014 jumlah bayi dengan Berat Badan Lahir Rendah mengalami peningkatan yaitu menjadi $2.2 \%$ diperoleh dari presentasi 20.465 bayi dari 948.797 bayi baru lahir yang di timbang. Angka tertinggi di Ciamis 5.5\% dan terendah di Kabupaten Bekasi 0.3\%, bisa disimpulkan bahwa pada tahun 2014 Kabupaten Ciamis menjadi penyumbang bayi berat badan lahir rendah (BBLR) tertinggi di Jawa Barat. ${ }^{3}$

Berdasarkan studi pendahuluan yang telah dilakukan di Dinas kesehatan Kabupaten Ciamis tahun 2017 dilaporkan ibu hamil yang mengalami anemia yaitu angka tertinggi di wilayah kerja puskesmas Sadananya 238 orang, Kawali Mukti 235 orang, Cihaurbeuti 185 orang, Payungsari 168 orang dan Baregbeg 154 orang sedangkan bayi yang lahir dengan Bayi Berat Lahir Rendah (BBLR) angka tertinggi berada di wilayah kerja Puskesmas Rancah 58 bayi, Rajadesa 52 bayi, Purwadadi 47 bayi, Baregbeg 39 bayi. Jumlah Keseluruhan 920 bayi lahir dengan BBLR dan 2981 orang ibu hamil mengalami anemia. ${ }^{5}$

Studi pendahuluan yang telah dilakukan di wilayah kerja Puskesmas Baregbeg diperoleh data dari laporan PWS KIA bulan Januari-Desember 2017, di peroleh 154 orang ibu hamil dengan anemia dan jumlah Bayi Baru Lahir Rendah (BBLR) 39 bayi. $^{6}$

Berdasarkan studi pendahuluan yang dilakukan terhadap 10 ibu hamil dapat diketahui bahwa 5 ibu hamil mengetahui tentang anemia tapi tidak terlalu paham bagaimana bahaya, risiko yang akan ditimbulkan begitupun penanganan tentang anemia sedangkan 5 ibu hamil belum mengetahui tentang anemia, gejala, risiko, dan penanganannya. Di wilayah kerja Puskesmas Baregbeg menurut laporan bulan Juni 2018 
dari sasaran ibu hamil 252 orang, 18 orang hamil trimester III usia kehamilan >37 minggu. ${ }^{6}$

Ada beberapa faktor yang mempengaruhi berat badan lahir rendah (BBLR), faktor-faktor yang berkaitan dengan ibu seperti umur ibu (kurang dari 20 th), umur kehamilan (trimester 2 dan 3), status gizi (anemia defisiensi $\mathrm{Fe}$ ). Selain itu yang tidak kalah pentingnya adalah faktor lingkungan seperti: pendidikan, pekerjaan, status sosial ekonomi, budaya dan pengetahuan ibu. ${ }^{1}$

Berdasarkan banyaknya data kejadian anemia pada ibu hamil dan kejadian BBLR di Wilayah kerja Baregbeg sehingga peneliti ingin mengkaji lebih dalam tentang bagaimana hubungan pengetahuan ibu hamil tentang anemia dengan risiko kejadian BBLR (Berat Badan Lahir Rendah) di Wilayah kerja Puskesmas Baregbeg. ${ }^{6}$

\section{METODE}

Penelitian ini merupakan penelitian deskriptif analitik yang menggunakan desain cross sectional study yaitu untuk melihat hubungan tingkat pengetahuan ibu hamil tentang anemia dengan risiko kejadian BBLR (Bayi Berat Lahir Rendah), yang masingmasing variabel diukur pada satu waktu yang sama.

Populasi dalam penelitian ini adalah semua ibu yang hamil trimester III usia kehamilan >37 minggu serta rutin memeriksakan kehamilan di Wilayah kerja Puskesmas Baregbeg bulan Juni 2018. Data di Wilayah kerja Puskesmas Baregbeg tahun 2018 sasaran ibu hamil Trimester III dengan usia kehamilan $>37$ minggu sebanyak 18 orang.

Teknik penentuan sampel yang digunakan adalah teknik total sampling, teknik penentuan sampel bila semua anggota populasi digunakan sebagai sampel. Hal ini sering dilakukan bila jumlah populasi relatif kecil atau penelitian yang ingin membuat generalisasi dengan kesalahan yang sangat kecil. Istilah lain total sampling adalah sensus, dimana semua anggota populasi dijadikan sampel. ${ }^{7}$ Jadi sampel yang digunakan dalam penelitian ini sebanyak 18 orang.
Akan tetapi yang menjadi responden penelitian hanya 15 orang karena $1 \mathrm{ibu}$ hamil sudah melahirkan dan 2 ibu hamil menolak untuk menjadi responden.

Lokasi penelitian dilakukan di Wilayah kerja Puskesmas Baregbeg. Sumber data yang digunakan untuk menganalisis permasalahan dalam penelitian ini adalah:

a. Data primer

Data primer merupakan data yang diperoleh sendiri oleh peneliti dari hasil pengukuran, pengamatan, survey dan lainlain. ${ }^{8}$ Data primer penelitian ini diperoleh dari hasil pengisian kuesioner kepada responden. Responden atau subjek yang diteliti adalah ibu hamil trimester III usia kehamilan >37 minggu di wilayah kerja Puskesmas Baregbeg.

b. Data sekunder

Data sekunder adalah data primer yang diperoleh dari pihak lain atau data primer yang sudah diolah oleh pengumpul data menjadi bentuk tabel atau diagram. Sumber data sekunder ini diperoleh dari data rekam medis yang diambil dari buku kohort di wilayah kerja Puskesmas Baregbeg bulan Juni 2018. ${ }^{9,10}$

Pengolahan data dilakukan dengan tahapan: Editing, Coding, Entry, Cleaning, Analisis Data (Analisis Univariat, Analisis Bivariat).

\section{HASIL}

Hasil penelitian ini telah dilaksanakan pada 15 orang ibu hamil trimester III usia kehamilan >37 minggu di Wilayah Kerja Puskesmas Baregbeg tahun 2018. Penelitian ini untuk mencari hubungan pengetahuan ibu hamil tentang anemia dengan risiko kejadian BBLR. Hasil analisis akan dituangkan dalam bentuk tabel sebagai berikut.

\section{Analisis Univariat}

Analisis Univariat dilakukan untuk mendeskripsikan variabel bebas dan variabel terikat, dalam penelitian ini adalah hubungan pengetahuan ibu hamil tentang anemia dengan risiko kejadian BBLR. Hasil penelitian adalah sebagai berikut. 
a. Karakteristik responden

Data umum yang menggambarkar karakteristik responden ibu hamil meliputi pendidikan dan pekerjaan.

\section{Tabel 1}

Distribusi Frekuensi Tingkat Pendidikan Di Wilayah Kerja Puskesmas Baregbeg Tahun 2018

\begin{tabular}{|c|c|c|}
\hline $\begin{array}{c}\text { Tingkat } \\
\text { Pendidikan }\end{array}$ & Frekuensi & Presentase \\
\hline $\begin{array}{c}\text { PERGURUAN } \\
\text { TINGGI }\end{array}$ & 2 & $13,3 \%$ \\
\hline SMA & 9 & $60 \%$ \\
\hline SMP & 3 & $20 \%$ \\
\hline SD & 1 & $6.7 \%$ \\
\hline JUMLAH & 15 & $100 \%$ \\
\hline
\end{tabular}

Sumber : Data Penelitian Tahun 2018.

Tabel 1 menunjukkan bahwa tingkat pendidikan di Wilayah Kerja Puskesmas Baregbeg Tahun 2018 dengan kategori perguruan tinggi 2 orang (13.3\%), SMA 9 orang (60\%), SMP 3 orang $(20 \%)$ dan SD 1 orang $(6,7 \%)$.

Tabel 2

Distribusi Frekuensi Tingkat Pekerjaan Di Wilayah Kerja Puskesmas Baregbeg Tahun 2018

\begin{tabular}{|c|c|c|}
\hline Pekerjaan & Frekuensi & Presentase \\
\hline Guru & 2 & $13,3 \%$ \\
\hline Ibu rumah tangga & 11 & $73,4 \%$ \\
\hline Wiraswasta & 2 & $13,3 \%$ \\
\hline JUMLAH & 15 & $100 \%$ \\
\hline
\end{tabular}

Sumber : Data Penelitian Tahun 2018.

Tabel 2 menunjukkan bahwa tingkat pekerjaan di Wilayah Kerja Puskesmas Baregbeg Tahun 2018 memiliki kategori Guru 2 orang $(13,3 \%)$ ibu rumah tangga 11 orang $73,4 \%$ dan 2 orang $(13,3 \%)$.

\section{b. Pengetahuan Ibu Tentang Anemia Tabel 3}

Distribusi Frekuensi Pengetahuan Ibu Hamil Tentang Anemia Di Wilayah Kerja Puskesmas Baregbeg Tahun 2018

\begin{tabular}{|c|c|c|}
\hline $\begin{array}{c}\text { Pengetahuan } \\
\text { Ibu Hamil } \\
\text { Tentang } \\
\text { Anemia }\end{array}$ & Frekuensi & Presentase \\
\hline Baik & 7 & $46,6 \%$ \\
\hline Cukup & 6 & $40 \%$ \\
\hline Kurang & 2 & $13,4 \%$ \\
\hline Jumlah & 15 & $100 \%$ \\
\hline
\end{tabular}

Sumber : Data Penelitian Tahun 2018. ${ }^{9}$

Tabel 3 menunjukkan bahwa sebagian besar pengetahuan ibu hamil tentang anemia di wilayah kerja Puskesmas Baregbeg diketahui 7 orang $(46.6 \%)$ dengan kategori pengetahuan baik, 6 orang $(40 \%)$ dengan kategori pengetahuan cukup dan 2 orang $(13,4 \%)$ dengan kategori kurang.

\section{c. Risiko Kejadian BBLR \\ Tabel 4}

Distribusi Frekuensi Risiko Kejadian BBLR

Di Wilayah Kerja Puskesmas Baregbeg Tahun 2018

\begin{tabular}{|c|c|c|}
\hline $\begin{array}{c}\text { Risiko } \\
\text { Kejadian } \\
\text { BBLR }\end{array}$ & Frekuensi & Presentase \\
\hline $\begin{array}{c}\text { Ada Risiko } \\
\text { BBLR }\end{array}$ & 5 & $33,3 \%$ \\
\hline $\begin{array}{c}\text { Tidak Ada } \\
\text { Risiko BBLR }\end{array}$ & 10 & $66.7 \%$ \\
\hline Jumlah & 15 & $100 \%$ \\
\hline
\end{tabular}

Sumber : Data Penelitian Tahun 2018.

Tabel 4 menunjukkan bahwa risiko kejadian BBLR di Wilayah Kerja Puskesmas Baregbeg Tahun 2018 memiliki kategori ada risiko BBLR 5 orang $(33,3 \%)$ dan tidak ada risiko BBLR 10 orang $(66,7 \%)$. 


\section{Analisis Bivariat}

Analisis Bivariat digunakan untuk melihat hubungan antara variabel sesuai dengan tujuan penelitian maka analisa bivariat dilakukan untuk melihat hubungan antara variabel dependen dengan independen dengan menggunakan uji Chi-Square. Hasil ini adalah sebagai berikut.

Tabel 5

\section{Hubungan Pengetahuan Ibu Hamil Tentang Anemia Dan Risiko Kejadian BBLR Di Wilayah Kerja Puskesmas Baregbeg Tahun 2018}

\begin{tabular}{|c|c|c|c|c|c|c|c|c|}
\hline \multirow[t]{3}{*}{ No } & \multirow{3}{*}{$\begin{array}{l}\text { Penget } \\
\text { ahuan } \\
\text { ibu } \\
\text { hamil } \\
\text { tentang } \\
\text { anemia }\end{array}$} & \multicolumn{4}{|c|}{ Risiko } & \multicolumn{2}{|c|}{ Total } & \multirow{3}{*}{$\begin{array}{c}\text { P } \\
\text { value }\end{array}$} \\
\hline & & \multicolumn{2}{|c|}{$\begin{array}{l}\text { Ada } \\
\text { Risiko }\end{array}$} & \multicolumn{2}{|c|}{$\begin{array}{c}\text { Tidak Ada } \\
\text { Risiko }\end{array}$} & & & \\
\hline & & $\mathbf{N}$ & $\%$ & $\mathbf{N}$ & $\%$ & $\mathbf{N}$ & $\%$ & \\
\hline 1 & Baik & 0 & 0 & 7 & 100 & 7 & 100 & 0,016 \\
\hline 2 & Cukup & 3 & 50 & 3 & 50 & 6 & 100 & \\
\hline 3 & Kurang & 2 & 100 & 0 & 0 & 2 & 100 & \\
\hline & Total & 5 & $\begin{array}{c}33 \\
3\end{array}$ & $\begin{array}{l}1 \\
0\end{array}$ & 66,7 & $\begin{array}{l}1 \\
5\end{array}$ & $\begin{array}{c}10 \\
0\end{array}$ & \\
\hline
\end{tabular}

Sumber : Data Penelitian Tahun 2018.

Tabel 4.5 menunjukkan bahwa pengetahuan ibu hamil tentang anemia sebanyak 7 orang (100\%) mempunyai pengetahuan baik sehingga ibu tidak berisiko melahirkan Berat Badan Lahir Rendah (BBLR) sedangkan ibu dengan pengetahuan kurang 2 orang (100\%) berisiko melahirkan Berat Badan Lahir Rendah.

Hasil pengujian statistik dengan menggunakan uji Chi-Square diperoleh nilai $\rho$ value sebesar 0,016 jika dibandingkan dengan $\alpha(0,05)$ maka nilai $\rho<$ nilai $\alpha(0.016<0,05)$, sehingga dapat disimpulkan Ha diterima dan Ho ditolak artinya terdapat hubungan yang bermakna antara pengetahuan ibu hamil tentang anemia dengan risiko kejadian BBLR di Wilayah Kerja Puskesmas Baregbeg tahun 2018.

\section{PEMBAHASAN}

\section{Karakteristik Responden}

Data tentang karakteristik responden dapat dilihat tabel 4.1 dan 4.2. Data pendidikan responden didapatkan sebanyak 9 orang (60\%) pendidikan terakhir SMA,

Menurut Wied Hary (1996) tingkat pendidikan turut pula menentukan mudah tidaknya seseorang menyerap dan memahami pengetahuan yang mereka peroleh, pada umumnya semakin tinggi pendidikan seseorang semakin baik pula pengetahuannya. Hasil penelitian pendidikan responden sudah bagus sesuai dengan anjuran pemerintah tentang wajib belajar 12 tahun.

Pekerjaan responden didapatkan sebanyak 11 orang $(73,4 \%)$ adalah ibu rumah tangga, memang secara tidak langsung pekerjaan turut andil dalam mempengaruhi tingkat pengetahuan seseorang, hal ini dikarenakan pekerjaan berhubungan erat dengan faktor interaksi sosial dan kebudayaan, sedangkan interaksi sosial dan budaya berhubungan erat dengan proses pertukaran informasi. Hal ini tentunya akan mempengaruhi tingkat pengetahuan seseorang.

\section{Tingkat Pengetahuan Ibu Hamil tentang anemia}

Anemia dalam kehamilan memberi pengaruh kurang baik bagi ibu, baik dalam kehamilan, persalinan, maupun nifas dan masa selanjutnya. Distribusi data tingkat pengetahuan dapat dilihat pada tabel 4.3. Dapat diketahui bahwa pengetahuan ibu hamil tentang anemia baik sebanyak 7 orang $(46,6 \%)$ orang yang memiliki pengetahuan baik tidak berisiko melahirkan BBLR. sedangkan 6 orang $(40 \%)$ dengan kategori pengetahuan cukup sehingga di dapat 3 orang berisiko kejadian BBLR dan 3 orang tidak berisiko BBLR dan 2 orang $(13,4 \%)$ dengan kategori kurang berisiko kejadian BBLR. ${ }^{11}$

Masa kehamilan merupakan masa dimana terjadi peningkatan asupan gizi pada ibu hamil 
yang jauh lebih banyak keadaan sebelum hamil. ${ }^{12}$ Zat gizi merupakan zat gizi yang penting dan dibutuhkan selama kehamilan adalah zat besi. ${ }^{13}$ Kebutuhan jaringan akan zat besi meningkat selama kehamilan untuk pembentukan plasenta, pertumbuhan janin, dan meningkatkan pengiriman oksigen ke jaringan yang pada waktu kehamilan terjadi peningkatan atau perluasan reaksi oksidasi dengan meningkatkan volume darah dan sel darah merah ibu. ${ }^{14,15}$

\section{Tingkat Risiko Kejadian BBLR}

Distribusi data tentang risiko atau tidak risiko kejadian BBLR dapat dilihat pada tabel 4.4 Dapat diketahui responden yang berisiko kejadian BBLR berjumlah 5 orang $(33,3 \%)$ dengan tingkat pengetahuan ibu cukup 3 orang dan kurang 2 orang. Sebagian ibu hamil dengan tingkat pengetahuan cukup dan kurang, selaras dengan kesadaran ibu tentang bahaya anemia. Berdasarkan pemeriksaan tinggi fundus uteri yang dilakukan oleh peneliti pada beberapa ibu hamil didapatkan risiko kejadian BBLR.

\section{Hubungan Tingkat Pengetahuan Ibu Hamil tentang Anemia dengan Risiko Kejadian BBLR di wilayah kerja Puskesmas Baregbeg.}

Hasil distribusi responden tentang tingkat pengetahuan ibu hamil tentang anemia dengan risiko kejadian BBLR di wilayah kerja Puskesmas Baregbeg dilihat pada tabel 4.5 Hasil uji statistik dengan korelasi uji-Square menunjukkan bahwa mayoritas responden yang memiliki tingkat pengetahuan tentang anemia yang baik dan tidak berisiko terhadap kejadian BBLR yaitu sebanyak 7 responden $(100 \%)$ karena ibu secara rutin mengikuti kelas ibu hamil, posyandu maupun melakukan pemeriksaan ke bidan sehingga ibu dengan mudah mendapatkan informasi tentang kehamilannya khususnya pengetahuan tentang anemia sehingga pengetahuan ibu selaras dengan perilaku ibu dan tidak berisiko kejadian BBLR, sedangkan responden dengan tingkat pengetahuan tentang anemia yang kurang dan berisiko terhadap kejadian BBLR adalah sebanyak 2 responden (100\%), karena ibu tidak rutin mengikuti kelas ibu hamil posyandu maupun melakukan pemeriksaan ke bidan sehingga tingkat pengetahuan ibu tentang kehamilan khususnya anemia rendah sehingga berpengaruh terhadap perilaku ibu untuk mencegah terjadinya anemia dan berisiko terjadi BBLR. Hasil uji korelasi uji-square diperoleh nilai signifikansi sebesar 0,016 . Nilai $\rho$ value sebesar 0,016 lebih kecil dari $\alpha(0,05)$. Hal ini menunjukkan bahwa terdapat hubungan yang signifikan antara tingkat pengetahuan ibu hamil tentang anemia dengan risiko kejadian BBLR.

Hasil penelitian tersebut memperkuat teori Amiruddin (2014) bahwa pengetahuan ibu hamil tentang anemia sangat penting sebagai salah satu upaya mencegah terjadinya anemia kehamilan dan BBLR sebagai dampaknya. Hal ini menunjukkan bahwa pengetahuan mempunyai pengaruh yang besar terhadap ibu hamil untuk mencegah terjadinya anemia pada saat hamil dan risiko kejadian BBLR. ${ }^{2}$

Uraian pembahasan diatas di wilayah Puskesmas Baregbeg memerlukan adanya suatu peran dari petugas kesehatan, salah satunya adalah bidan khususnya bidan di komunitas dalam upaya peningkatan pengetahuan dari masyarakat secara menyeluruh. Bidan berperan sebagai pendidik baik secara langsung dengan memberi penyuluhan dan pendidikan kesehatan kepada ibu hamil. ${ }^{16}$ Pengetahuan yang diberikan akan membantu ibu untuk meningkatkan pengetahuan tentang anemia selama ibu hamil dan mengurangi risiko kejadian BBLR. ${ }^{17}$ Bidan bekerja secara koordinasi dengan para kader desa sehingga diharapkan nantinya pendekatan-pendekatan kepada masyarakat dapat menghasilkan kerjasama yang baik dan memiliki satu tujuan yaitu menekan AKI yang masih banyak di Indonesia.

\section{KESIMPULAN}

Kesimpulan yang dapat diambil dari penelitian ini adalah sebagai berikut.

1. Pendidikan ibu hamil trimester III usia kehamilan >37 minggu di wilayah kerja Puskesmas Baregbeg tahun 2018, diketahui bahwa hampir sebagian dari responden atau sebanyak 9 orang (60\%) dengan kategori tingkat pendidikan SMA. 
2. Pekerjaan ibu hamil trimester III usia kehamilan >37 minggu di wilayah kerja Puskesmas Baregbeg tahun 2018, diketahui hampir sebagian dari responden atau sebanyak 11 orang $(73,4 \%)$ dengan kategori pekerjaannya sebagai ibu rumah tangga.

3. Pengetahuan ibu hamil tentang anemia di Wilayah Kerja Puskesmas Baregbeg tahun 2018, diketahui sebagian sebagian responden atau sebanyak 7 orang $(46,6 \%)$ dengan kategori baik.

4. Risiko kejadian BBLR pada ibu hamil trimester III usia kehamilan >37 minggu di wilayah kerja Puskesmas Baregbeg tahun 2018, diketahui bahwa sebagian dari responden atau sebanyak 10 orang (66.7\%) dengan kategori tidak berisiko kejadian BBLR.

5. Terdapat hubungan yang bermakna antara pengetahuan ibu hamil tentang anemia dengan risiko kejadian BBLR di wilayah kerja Puskesmas Baregbeg tahun 2018 dengan Hasil uji korelasi uji Chi-Square Diperoleh nilai $\rho$ value sebesar $0,016<\alpha$ $(0,05)$.

\section{SARAN}

Saran yang diberikan terkait dengan hasil dan pembahasan dalam penelitian ini adalah sebagai berikut.

\section{Bagi Peneliti}

Diharapkan dapat dijadikan pembelajaran dari aplikasi yang diperoleh di bangku kuliah, khususnya tentang metode penelitian.

2. Bagi Institusi Pendidikan

Diharapkan dapat dijadikan sebagai bahan rujukan agar dapat dimanfaatkan sebagai bahan perbandingan untuk angkatan berikutnya.

3. Bagi Institusi Pelayanan

Penelitian ini menambah informasi dan data tentang hubungan tingkat pengetahuan ibu hamil tentang anemia dengan risiko kejadian BBLR. Bidan maupun tenaga kesehatan lainnya di komunitas diharapkan dapat meningkatkan pelayanan pada ibu hamil dan pemberian promosi dan preventif kesehatan.

\section{Bagi Masyarakat}

Responden dalam penelitian ini yaitu ibu hamil dengan tingkat pengetahuan cukup dan kurang sehingga akan berisiko kejadian BBLR diharapkan memperhatikan kehamilannya yang tergolong dalam kehamilan risiko tinggi. Keluarga dan suami diharapkan turut memperhatikan kesehatan ibu dan bayinya selama hamil.

\section{DAFTAR PUSTAKA}

1. Proverawati A. Anemia dan Anemia kehamilan. Yogyakarta: Nuha Medika. 2011:136-7.

2. Amiruddin R. Determinan Kesehatan Ibu dan Anak. Jakarta: CV Trans Info Media. 2014.

3. Barat DKPJ. Profil Kesehatan Provinsi Jawa Barat Tahun 2012. Bandung: Dinas Kesehatan Provinsi Jawa Barat. 2012.

4. Scholl TO. Maternal iron status: relation to fetal growth, length of gestation, and iron endowment of the neonate. Nutrition reviews. 2011;69(suppl_1):S23-S9.

5. Ciamis DK. Profil Dinas Kesehatan Kabupaten Ciamis tahun 20172017.

6. Baregbeg P. Profil Puskesmas Baregbeg tahun 20172017.

7. Suharsimi A. Prosedur penelitian suatu pendekatan praktik. Jakarta: Rineka Cipta. 2006.

8. Notoatmodjo S. Metodologi penelitian kesehatan. Jakarta: rineka cipta; 2010.

9. Baregbeg P. Laporan PWS KIA Puskesmas Baregbeg Bulan Januari Tahun 2017. 2018.

10. Arikunto S. Prosedur Penelitian Pendidikan. Jakarta: PT Rineka Cipta. 2010. 
11. Djaja S. Penyakit penyebab kematian bayi baru lahir (neonatal) dan sistem pelayanan kesehatan yang berkaitan di Indonesia. 2003.

12. Yılmaz E, Korucuoğlu Ü, Acar A, Bozkurt N, Biri A. Aplastic anemia and pregnancy: Case report.

13. Marmi d. Asuhan Kebidanan Patologi. Yogyakarta: Pustaka Pelajar; 2014.

14. Departemen Kesehatan R. Pedoman umum gizi seimbang. Jakarta: Direktorat Jenderal Bina Kesehatan Masyarakat Direktorat Gizi Masyarakat. 2003.

15. Sohiniah. Anemia dalam Kehamilan dan Penanggulangannya. Jakarta: Gramedia; 2006.

16. Sistiarani C. Faktor maternal dan kualitas pelayanan antenatal yang berisiko terhadap kejadian berat badan lahir rendah (BBLR) studi pada ibu yang periksa hamil ke tenaga kesehatan dan melahirkan di rsud banyumas tahun 2008: Program Pascasarjana Universitas Diponegoro; 2008.

17. Nirwana AB. Kapita Selekta Kehamilan. Yogyakarta: Nuha Medika. 2011. 